\title{
Quantifying Object and Material Surface Areas in Residences
}

\author{
Alfred T. Hodgson, Katherine Y. Ming and Brett C. Singer \\ Indoor Environment and Atmospheric Sciences Departments, Environmental Energy \\ Technologies Division, Lawrence Berkeley National Laboratory, Berkeley, CA 94720, \\ USA
}

December 2004

\begin{abstract}
The dynamic behavior of volatile organic compounds (VOCs) in indoor environments depends, in part, on sorptive interactions between VOCs in the gas phase and material surfaces. Since information on the types and quantities of interior material surfaces is not generally available, this pilot-scale study was conducted in occupied residences to develop and demonstrate a method for quantifying surface areas of objects and materials in rooms. Access to 33 rooms in nine residences consisting of bathrooms, bedroom/offices and common areas was solicited from among research group members living in the East San Francisco Bay Area. A systematic approach was implemented for measuring rooms and objects from $300 \mathrm{~cm}^{2}$ and larger. The ventilated air volumes of the rooms were estimated and surface area-to-volume ratios were calculated for objects and materials, each segregated into 20 or more categories. Total surface area-to-volume ratios also were determined for each room. The bathrooms had the highest total surface area-to-volume ratios. Bedrooms generally had higher ratios than common areas consisting of kitchens, living/dining rooms and transitional rooms. Total surface area-tovolume ratios for the 12 bedrooms ranged between 2.3 and $4.7 \mathrm{~m}^{2} \mathrm{~m}^{-3}$. The importance of individual objects and materials with respect to sorption will depend upon the sorption coefficients for the various VOC/materials combinations. When combined, the highly permeable material categories, which may contribute to significant interactions, had a median ratio of about $0.5 \mathrm{~m}^{2} \mathrm{~m}^{-3}$ for all three types of rooms.
\end{abstract}

\section{Introduction}

Numerous studies have been conducted to better understand human exposures to toxic volatile organic compounds (VOCs). Since the U.S. population spends, on average, about $90 \%$ of its time in residences and other buildings (Klepeis et al., 2001), much of the exposures to VOCs occur indoors. Outdoor air contaminants penetrate buildings through 
ventilation and infiltration, and numerous indoor VOC sources are active on various time scales. The relatively low outdoor air change rates in most buildings prevent the rapid dispersal of indoor generated air contaminants often resulting in indoor concentrations that are substantially higher than outdoor concentrations (Lai et al., 2000). In addition to ventilation, other physical and chemical processes modify the temporal composition and concentrations of VOCs within buildings. These processes include heterogeneous and homogeneous chemical reactions that may produce secondary gas-phase contaminants (Weschler et al., 1992; Weschler and Shields, 2000); changes in gas-particle partitioning; and sorptive interactions between gases and interior material surfaces including surfaces in mechanical air-handling systems (Tichenor et al, 1991; Van Der Wal et al., 1998; Bouhamra and Elkilani, 1999). Understanding these dynamic processes is essential for more accurate predictions of potential indoor exposures to VOCs.

Sorptive processes in a simulated residential room were shown to affect the temporal patterns of VOC constituents of environmental tobacco smoke (ETS) (Singer et al., 2002, 2003). For less-volatile ETS compounds, such as naphthalene, cresol, and nicotine, sorption to room surfaces during active smoking and later re-emission substantially shifted potential exposures to subsequent non-smoking periods. In the same simulated room, another study was conducted to derive models describing the sorptive behavior of 20 VOCs representative of a wide range of volatility and chemical functionality (Singer et al., 2004). For many of the VOCs, including $\mathrm{C}_{8}-\mathrm{C}_{10}$ aromatic hydrocarbons, terpene hydrocarbons and pyridine, adsorption rates were comparable to typical air change rates. For the less-volatile constituents, adsorption rates were higher, and 95 to $>99 \%$ of the mass partitioned to the sorbed phase at equilibrium. These results demonstrated that sorption processes in residences and other buildings likely have substantial impacts on temporal air concentration profiles for many common indoor VOCs.

Sorption onto indoor surfaces has been investigated primarily through experiments in small chambers with specific combinations of individual household materials and individual VOCs. The data have been fit to equations to obtain key parameter values, yielding semi-empirical sorption models. In an extensive study, Won et al. (2001) measured adsorption and desorption rate coefficients for eight VOCs interacting with gypsum wallboard, carpet and cushion, acoustic ceiling tile, wood flooring, vinyl flooring, and fiberglass.

One objective of small- and large-scale sorption experiments is to obtain model parameters that can be used to simulate computationally the potential effects of sorption in a building containing multiple materials. This scale-up modeling approach requires 
information on the types and quantities of material surfaces in residences and other buildings. However, such information is not currently available. Thus, this pilot study was conducted in occupied residences to develop and demonstrate a method for quantifying surface areas of objects and materials in rooms.

\section{Methods}

\section{Residences and Rooms}

Volunteers willing to allow their residences and rooms to be studied were solicited from among the Indoor Environment Department and Atmospheric Sciences Department research groups at Lawrence Berkeley National Laboratory. In total, access to nine different residences was obtained. The characteristics of the study residences are listed in Table 1. All of the residences were located in the East San Francisco Bay Area. All of the residences, except one, were at least 50 years old. There were five detached singlefamily houses, three apartments and one dormitory room. The occupants were all adults except in one single-family house. A total of 33 rooms were studied. In order to obtain a wide range of objects and materials, rooms with varying functions were selected. There were 12 common areas defined to include kitchens, living and dining rooms, hallways and foyers, 14 bedrooms/offices of which two functioned solely as an office, and seven bathrooms. Summary statistics (range and median) for the floor areas by room type are shown in Table 2.

\section{Measurement Sequence}

To efficiently measure surface areas within a room, a sequence of steps (Table 3 ) was followed to assure that no objects of significance were over looked. The preliminary steps consisted of drawing a floor plan and listing all of the objects in the room. Next, objects were measured generally in order of descending size. The first surface areas measured were the components of the room envelope (floor, walls, ceiling). The next items measured were features (windows, doors, trim, etc.) followed by furniture pieces, and miscellaneous large objects. Finally, smaller objects between $\sim 300$ and $\sim 2000 \mathrm{~cm}^{2}$ were included by counting the numbers of such objects in each of three size bins. Individual objects less than $\sim 300 \mathrm{~cm}^{2}$ were ignored.

\section{Dimensions}

Measurements of predominantly straight edges were made using a metric metal tape measure. Curved or irregular edges (e.g., the circumference of a trash can, rounded molding, etc.) were measured with a metric cloth measuring tape. Two efficiencies were 
used to expedite the measuring process and to accommodate surfaces that were not exactly rectangular, circular, or cylindrical. The first involved objects that had a consistent dimension throughout several segments. For these, the lengths of segments were added together and their sum was entered into the database. The shared dimension also was entered into the same record. For example, when measuring the baseboard trim along the walls of a room, the entries were the summed lengths of the walls and the height of the baseboard. The second measurement efficiency was to approximate the dimensions of complex shapes.

\section{Surface Areas}

The data collection and entry conventions for surface areas are presented in Table 4. All surface areas were reduced into one of four basic shapes: rectangular, circular, cylindrical, or spherical. The one or two dimensions that characterized the areas of these shapes (i.e., length, diameter or circumference) were measured. Data entry naming conventions according to the shape and orientation of an object surface were followed to allow for easy verification and future reference. The labels most often used for identification of the different surfaces were front, back, top, bottom and side when viewed from the middle of the room.

All three-dimensional objects were broken down into their two-dimensional surface area components, which were characterized independently. For example, the external area of a rectangular box sitting on the floor was characterized as the two dimensions of each distinct side times the number of sides having those dimensions. Objects containing more complicated rectilinear shapes, such as chairs, were characterized in a similar reductive manner. Cylindrical legs, when unrolled, the cushion, and back of the chair were all considered rectangles. For complicated objects, additional labels for identification of the different surfaces were used, e.g., inside, large side, small side, curved side, etc.

A concept of negative area was introduced to account for surfaces with voids or consisting of a variety of materials and for surfaces that were not directly exposed to the ventilated room volume. For example, the area of a wall was first determined by measurement of the basic length and height dimensions. But, in many cases, the actual surface area of the wall material (e.g., painted wallboard) was reduced due to the presence of an open doorway, a passage door, a window, attached artwork, furniture placed against the wall, etc. The dimensions of the features that were either non-existent (e.g. an open doorway), composed of a different material (e.g. windows), or not directly 
exposed to room air (e.g. wall area behind a bookcase) were measured and the calculated areas were treated in the database as negative wall areas and were subtracted from the primary wall area calculated from the length and height dimensions.

In deciding whether a surface was directly exposed to the room air volume, we applied a convention that if two objects were less than a centimeter apart, both opposing surfaces were not exposed. Consequently, the dimensions of these surfaces were either not entered into the database or were used to calculate negative area. For example, if a bookcase was less than a centimeter away from the wall, the dimensions of the back of the bookcase were not included in the bookcase entries. The dimensions of the wall that the bookcase covered, however, were entered into the database and the calculated area was indicated as negative wall area.

A grouping approach was applied to estimate the combined surface areas of numerous identical surfaces within an individual object or of numerous small similar objects. For each group, a surface that appeared to represent the average size for the group was selected as a representative sample. The dimensions of the sample were determined and entered into the database along with the number of objects within the group. Examples of groups included: framed artwork/pictures, baskets, boxes, legs on a chair, and bars on a crib. To avoid having to measure individually many small items, objects with exposed areas between 300 and $2000 \mathrm{~cm}^{2}$ were grouped into three convenient size bins: 300 to 600 $\mathrm{cm}^{2}, 601$ to $1400 \mathrm{~cm}^{2}$, and 1401 to $2000 \mathrm{~cm}^{2}$. For reference, the lengths of square objects with these areas are 17 to $24 \mathrm{~cm}, 25$ to $37 \mathrm{~cm}$, and 38 to $44 \mathrm{~cm}$, respectively. Typical objects that fell into these three categories are listed in Table 5.

\section{Volumes}

In order to obtain an estimate of the ventilated air volume of a room, the volumes of the major objects within the room were calculated and subtracted from the room volume determined by its basic dimensions (i.e., length, width and ceiling height). Significant objects in a room that were subtracted included the larger pieces of furniture and appliances such as dressers, beds, bookcases, cupboards, and refrigerators. For large furniture pieces that were not solid blocks, such as a bookcase in which the books only occupied a portion of the volume, volumes were estimated. Small or thin pieces of furniture such as dining chairs or tables were not subtracted. The estimates of ventilated air volumes were used to calculate the surface area-to-volume ratios. 


\section{Object and Material Characterization}

Each individually measured object in a room was assigned to one of 23 object subcategories (Table 6). These subcategories were grouped into three broad categories (plus a miscellaneous category): 1) the basic room envelope; 2 ) envelope features or details such as windows, doors, area rugs; and 3) large standing objects consisting of furniture, appliances and fixtures. The subcategories grouped under the miscellaneous heading were used to describe the smaller distributed objects in the rooms.

Each object surface was characterized into one of 20 material subcategories (Table 7). These subcategories were grouped into four broad categories (plus a miscellaneous category), which were loosely based on estimated material sorptive capacities. Some subcategories were distinct, such as glass, porcelain, tile, painted wallboard, wicker, and paper. Other subcategories were more complex combinations of different types of material surfaces such as finished wood, which included finished wood floors, other finished woods as well as veneers and laminate materials, and plastic, which included vinyl flooring, electronic equipment, shower curtains, plastic bags, and plastic bottles as examples. Fabrics, carpets, upholstery, and related materials were divided into three subcategories, roughly based on their fleeciness and thickness. Cloth class 1 consisted of thin fabrics, such as t-shirts and single layer drapery. Cloth class 2 consisted of middleweight fabrics such as sweatshirts and towels, and cloth class 3 consisted of heavy-weight fabrics such as blankets and thick coats as well as stuffed fabrics (pillows and cushions), padded and unpadded carpet and upholstered foam objects.

\section{Data Handling}

Data was entered, organized and manipulated in a relational database (Access 2000®, Microsoft Corp.) consisting of several tables. An object identification table contained information describing all objects with surface areas greater than $\sim 2000 \mathrm{~cm}^{2}$. These objects were given unique identifiers and were categorized by type (Table 6). An object surface area table contained the dimensions and the material categories for all the object surfaces (Table 4). This information was used to calculate total surface areas for rooms by type of objects and by type of material. A volume table contained the dimensions of the room and the volumes of large objects. A room table held information about the room. 


\section{Results}

\section{Study Limitations}

This investigation was designed as a pilot study. Although a variety of residences including small apartments and relatively large houses were studied, the sample of rooms was obtained by convenience and is not representative of any population of rooms. All of the residences were located in an established, densely populated urban area. With a single exception, all of the residences were more than 50 years old.

\section{Uncertainties}

As described, two efficiencies were used to estimate the dimensions and surface areas of some objects. These efficiencies were the grouping of small objects by approximate size categories and the estimation of dimensions of objects with uneven or jagged edges. The uncertainties introduced by these two procedures were evaluated. Some small objects that were grouped into the three size categories also were measured individually. As shown in Table 8 , the total estimated surface area was about $6 \%$ less than the total measured surface area, with the uncertainties for the individual size categories ranging approximately between $\pm 20 \%$. In another evaluation, dimensions of books on a bookcase shelf were both accurately measured and estimated based on an assumed average height and then the computed surface areas were compared. The estimated surface area, $4,950 \mathrm{~cm}^{2}$, exceeded the actual area, $4,720 \mathrm{~cm}^{2}$, by about $5 \%$.

\section{Surface-to-Volume Ratios}

There were a number of commonly encountered objects comprising the room envelope, envelope features, large standing objects and miscellaneous objects in the rooms. The surface area-to-volume ratios for 13 easily recognized subcategories of these commonly encountered objects are listed in Table 9 by room type. The summary statistics show the median, range and number of observations for each subcategory in the common areas, bedroom/offices, and bathrooms. The walls and ceilings of the rooms had median ratios of about $1 \mathrm{~m}^{2} \mathrm{~m}^{-3}$, or higher. Hard surface furniture had relatively high median ratios in all room types. Bathrooms had distinctly higher ratios for tile and ceramic fixtures, and miscellaneous smaller objects.

For each room, the surface areas of all the objects within the room were summed and the total surface area-to-volume ratio was calculated using the estimated ventilated volume. These values are plotted versus floor area in Figure 1. For comparison, the total envelope surface area-to-volume ratios are plotted for unfurnished square spaces ranging 
in size from 2 to $38 \mathrm{~m}^{2}$ with an assumed 2.43-m (8-ft) ceiling height. Bathrooms had the highest surface area-to-volume ratios, ranging between 4.6 and $5.4 \mathrm{~m}^{2} \mathrm{~m}^{-3}$, due to their small size and relatively high areas of small objects such as towels and plastic bottles. These values generally were about a factor of two higher than the surface area-to-volume ratios for the envelope of comparably sized square rooms. Bedroom/offices tended to have relatively large pieces of furniture. The ratios for the bedroom/offices ranged between 2.3 and $4.7 \mathrm{~m}^{2} \mathrm{~m}^{-3}$ and generally decreased with increasing size. These values ranged from about two to four times the values for the envelope of comparably sized square rooms. The common areas serving a variety of functions had similar ratios with no apparent trend versus floor area. For example, hallways were small in size but did not contain many large objects. Thus, their ratios were small compared to other comparably sized rooms in the study residences. The ratios for all common areas ranged between 2.5 and $3.3 \mathrm{~m}^{2} \mathrm{~m}^{-3}$.

For the 12 bedrooms (excluding offices), both the total surface area-to-volume ratios and the ratios for categories of commonly encountered objects (five identified subcategories and a miscellaneous category) are shown in Figure 2. The bedrooms are ordered from smallest $\left(9.2 \mathrm{~m}^{2}\right)$ to largest $\left(20.7 \mathrm{~m}^{2}\right)$ floor area. Among the categorized objects, the combined wall and ceiling areas and the areas of hard surface furniture were generally predominant. Upholstered furniture and beds accounted for relatively small fractions of the total surface area-to-volume ratios. Miscellaneous objects accounted for relatively large fractions of the total ratios.

The surface area-to-volume ratios for 12 commonly encountered material subcategories are listed in Table 10 by room type. The summary statistics show the median, range and number of observations for each subcategory in the common areas, bedroom/offices, and bathrooms. The median ratios for the permeable walls and ceilings of the rooms are nearly identical to median ratios for walls and ceilings in Table 9 of categorized objects. The bathrooms had high ratios of impermeable materials with the median ratio for ceramic, porcelain and tile exceeding $1 \mathrm{~m}^{2} \mathrm{~m}^{-3}$. Permeable hard surface materials consisting of PVC plastic, other plastic, finished and unfinished wood, and painted wood had combined median ratios that approached or exceeded $1.5 \mathrm{~m}^{2} \mathrm{~m}^{-3}$. The combined median ratios for highly permeable fabrics, upholstery, and carpets were approximately $0.5 \mathrm{~m}^{2} \mathrm{~m}^{-3}$ in the three room types. 


\section{Discussion}

This pilot scale demonstration of a methodology to quantify the exposed surface areas of household objects and materials has provided information for a limited number of rooms of several types. Although, the applicability of the results to a broad population of houses is not known, several observations may be generally applicable to U.S. houses. The small bathrooms had high surface area-to-volume ratios. The surfaces in the bathrooms were dominated by the walls and ceiling and by impermeable materials such as ceramic, porcelain, and tile objects. Bedrooms generally had higher surface area-tovolume ratios than the common areas in the houses. Surface area-to-volume ratios for bedrooms of different sizes varied by about a factor of two. The painted and papered walls and ceilings dominated surface areas in all rooms. This finding is potentially important with respect to the sorption and re-emission of VOCs as the underlying materials consisting of plaster and gypsum board are known to be highly permeable to VOCs (Meininghaus et al, 2000; Tiffonnet et al., 2000; Meininghaus and Uhde, 2002). Hard surfaces such as finished and unfinished wood and various plastics had surface area-to-volume ratios that exceeded or were approximately comparable to ratios for the walls and ceilings. Some of these may be important with respect to VOC sorption and reemission. For example, VOCs diffuse in solid materials such as vinyl flooring (Cox et al., 2002). For some VOC/material combinations, diffusion has the potential to significantly alter the temporal profile of airborne VOC concentrations (Zhao et al., 2002). Plush, highly permeable objects and materials had moderately high surface areato-volume ratios in bedrooms, bathrooms, and common areas. The importance of these surfaces with respect to sorption is expected to depend on the type of fabric and the presence of backing materials. For example, carpet with an underlying polyurethane foam carpet cushion, has been shown to be much more important with respect to sorption of VOCs than carpet alone and or other indoor materials (Won et al., 2000, 2001).

The results of this study currently are being used to help interpret the results of a field investigation of VOC sorption dynamics in residences. A mixture of low toxicity VOCs was introduced into sealed rooms in houses. Air change rates and VOC concentrations were measured over time following the releases, and the data were used to derive sorption rate coefficients. Relationships with the quantities and surface area-to-volume ratios of specific object or material subcategories in the rooms are being explored. 


\section{Acknowledgements}

Katherine Ming was supported through the Science Undergraduate Laboratory Internships (SULI) program, Center for Science and Engineering Education at Berkeley Lab, Office of Science, U.S. Department of Energy (DOE). The U.S. Department of Homeland Security, Science and Technology Directorate and the U.S. DOE, Assistant Secretary for Fossil Energy, Office of Natural Gas and Petroleum Technology, through the National Petroleum Technology Office, provided additional support for this study. All work was conducted under U.S. DOE Contract No. DE-AC03-76SF00098. The authors thank Tosh Hotchi of LBNL for technical assistance and David Faulkner and Rick Diamond of LBNL for their reviews.

\section{References}

Bouhamra, W. and A. Elkilani. 1999. Development of a model for the estimation of indoor volatile organic compound concentrations based on experimental sorption parameters. Environ. Sci. Technol. 33: 2100-2105.

Cox. S.S., J.C. Little and A.T. Hodgson. 2002. Predicting the emission rate of volatile organic compounds from vinyl flooring. Environ. Sci. Technol. 36: 709-714.

Klepeis, N.E, W.C. Nelson, W.R. Ott, et al. 2001. The National Human Activity Pattern Survey (NHAPS): A resource for assessing exposure to environmental pollutants. $J$. Expos. Anal.Environ. Epidemiol. 11: 231-252.

Lai, A.C.K., T.L. Thatcher and W.W. Nazaroff. 2000. Inhalation transfer factors for air pollution health-risk assessments. J. Air Waste Manage. Assoc. 50: 1688-1699.

Meininghaus R and Uhde E. 2002. Diffusion studies of VOC mixtures in a building material. Indoor Air 12: 215-222.

Meininghaus R, Gunnarsen L and Knudsen HN. 2000. Diffusion and sorption of volatile organic compounds in building materials - Impact on indoor air quality. Environ. Sci. Technol. 34: 3101-3108.

Singer, B.C., A.T. Hodgson, K.S. Guevarra, E.L. Hawley and W.W. Nazaroff. 2002. Gasphase organics in environmental tobacco smoke: 1. Effects of smoking rate, ventilation, and furnishing level on emission factors. Environ. Sci. Technol. 36: 846853.

Singer, B.C., A.T. Hodgson and W.W. Nazaroff. 2003. Gas-phase organics in environmental tobacco smoke: 2. Exposure-relevant emission factors and indirect 
exposures from habitual smoking. Atmospheric Environment 37: 5551-5561.

Singer, B.C., K.L. Revzan, T. Hotchi, A.T. Hodgson and N.J. Brown. 2004. Sorption of organic gases in a furnished room. Atmospheric Environment 38: 2483-2494.

Tichenor, B.A., Z. Guo, J.E. Dunn, L.E. Sparks and M.A. Mason. 1991. The interaction of vapor phase organic compounds with indoor sinks. Indoor Air 1: 23-35.

Tiffonnet AL, Blondeau P and Allard F. 2000. Assessment of contaminant diffusivities in building materials from porosity tests. In Seppänen, $\mathrm{O}$ and Säteri J (eds.) Healthy Buildings 2000. Proceedings, Espoo, Finland, Vol. 4, pp. 199-204.

Van Der Wal, J.F., A.W. Hoogeveen and L. van Leeuwen. 1998. A quick screening method for sorption effects of volatile organic compounds on indoor materials. Indoor Air 8: 103-112.

Weschler, C.J., A.T. Hodgson and J.D. Wooley. 1992. Indoor chemistry: Ozone, volatile organic compounds, and carpets. Environ. Sci. Technol. 26: 2371-2377.

Weschler, C.J. and H.C. Shields. 2000. The influence of ventilation on reactions among indoor pollutants: Modeling and experimental observations. Indoor Air 10: 92-100.

Won D., R.L. Corsi and M. Rynes. 2000. New indoor carpet as an adsorptive reservoir for volatile organic compounds. Environ. Sci. Technol. 34: 4193-4198.

Won, D., R.L. Corsi and M. Rynes. 2001. Sorptive interactions between VOCs and indoor materials. Indoor Air 11: 246-256.

Zhao, D., J.C. Little and A.T. Hodgson. 2002. Modeling the reversible, diffusive sink effect in response to transient contaminant sources. Indoor Air 12: 184-190. 
Table 1. Characteristics of study residences

\begin{tabular}{cccccc}
\hline & Residence & Age & No. & \multicolumn{2}{c}{ Rooms (Common/BR/Bath) } \\
\cline { 5 - 6 } Type & (years) & Occupants* & $\begin{array}{c}\text { No. in } \\
\text { House }\end{array}$ & $\begin{array}{c}\text { No. } \\
\text { Studied }\end{array}$ \\
\hline SF 1 & Single Family & 90 & 2A \& 2M & $5 / 4 / 2$ & $4 / 3 / 2$ \\
SF 2 & Single Family & 60 & 2A & $2 / 2 / 2$ & $2 / 2 / 2$ \\
SF 3 & Single Family & 100 & $4 \mathrm{~A}$ & $5 / 4 / 1.5$ & $3 / 4 / 1$ \\
SF 4 & Single Family & $50-60$ & $3 \mathrm{~A}$ & $7 / 5 / 2.5$ & $1 / 0 / 0$ \\
SF 5 & Single Family & 74 & $2 \mathrm{~A}$ & $9 / 6 / 3$ & $0 / 2 / 2$ \\
A 1 & Apartment & 50 & $1 \mathrm{~A}$ & $1 / 1 / 1$ & $0 / 1 / 0$ \\
A 2 & Apartment & $70-80$ & $1 \mathrm{~A}$ & $1 / 0 / 1$ & $1 / 0 / 0$ \\
A 3 & Apartment & 20 & $1 \mathrm{~A}$ & $1 / 0 / 1$ & $1 / 0 / 0$ \\
D & Dormitory Rm. & 80 & $2 \mathrm{~A}$ & $0 / 1 / 0$ & $0 / 1 / 0$ \\
\hline
\end{tabular}

$* \mathrm{~A}=$ Adults; $\mathrm{M}=$ Minors

Table 2. Summary statistics for the floor areas of the 33 study rooms by room type

\begin{tabular}{lcccc}
\hline Room Type & Category* & No. & $\begin{array}{c}\text { Median Size } \\
\mathbf{( m}^{\mathbf{2}} \mathbf{c}\end{array}$ & $\begin{array}{c}\text { Size Range } \\
\mathbf{( m}^{\mathbf{2}} \mathbf{)}\end{array}$ \\
\hline $\begin{array}{l}\text { Living/dining room } \\
\text { Living/dining room with } \\
\text { kitchen }\end{array}$ & Common & 4 & 22.4 & $18.7-27.0$ \\
$\begin{array}{l}\text { Enclosed kitchen } \\
\text { Hallway/foyer }\end{array}$ & Common & 3 & 29.7 & $24.2-38.0$ \\
Bedroom & Common & 4 & 17.8 & 17.8 \\
Office & Bedrm/Off & 12 & 14.0 & $5.2-13.8$ \\
Bathroom & Bedrm/Off & 2 & 11.0 & $8.2-20.7$ \\
\hline
\end{tabular}

*Study rooms were assigned to three categories: common area, bedroom/office, and bathroom 
Table 3. Sequence of steps followed to measure surface areas of objects in a room

\section{Step Description}

1 Draw floor plan of room including large pieces of furniture \& fixtures

2 Prepare checklist of all objects in room

3 Measure envelope, features \& objects in following sequence:

a. Walls

b. Ceiling \& floor (usually the same, but kitchen and bath floor area is defined by floor covering area). Write room dimensions on floor plan

c. Doors \& windows including trim

d. Doors \& windows minus trim

e. Door \& window trim

f. Wall trim

g. Furniture \& fixtures following order of items in checklist

h. Other large objects following order of items in checklist

i. Objects hanging on walls

4 Count by category small objects that are not individually measured

$5 \quad$ Record volumes of large objects (e.g., furnishings)

Table 4. Data entry conventions for objects of different shapes

\begin{tabular}{lccccc}
\hline $\begin{array}{l}\text { Primary } \\
\text { Shape }\end{array}$ & $\begin{array}{c}\text { Surface Area } \\
\text { Descriptor }\end{array}$ & $\begin{array}{c}\text { Add or } \\
\text { Subtract }\end{array}$ & Dimension 1 & Dimension 2 & $\begin{array}{c}\text { No. of } \\
\text { Surfaces }\end{array}$ \\
\hline Rectangular & Front/back & $+/-$ & Width & Height & $\#$ \\
Rectangular & Top/bottom & $+/-$ & Width & Depth & $\#$ \\
Rectangular & Side & $+/-$ & Depth & Height & $\#$ \\
Circular & Top/bottom & $+/-$ & Diameter/2 & $\pi$ & $\#$ \\
& or front & & Circumference & Height & $\#$ \\
Cylindrical & Top/Side & & Diameter & $2 \pi$ & $\#$ \\
Spherical & & & & &
\end{tabular}


Table 5. Three categories used to estimate areas of small objects with surface areas less than $0.2 \mathrm{~m}^{2}$ with examples for each category

\begin{tabular}{ll}
\hline Area Category & Example Objects \\
\hline 300 to $600 \mathrm{~cm}^{2}$ & Soda can, mouse pad, shampoo bottle \\
601 to $1400 \mathrm{~cm}^{2}$ & 1-L Water bottle, phone, tall glass \\
1401 to $1900 \mathrm{~cm}^{2}$ & Notebook computer on desk, textbook \\
\hline
\end{tabular}

Table 6. Categories and subcategories used to describe objects in a room

\begin{tabular}{cccc}
\hline Envelope & $\begin{array}{c}\text { Envelope } \\
\text { Feature }\end{array}$ & $\begin{array}{c}\text { Standing } \\
\text { Item }\end{array}$ & Misc. \\
\hline Wall & Window & Bed & Large trash can \\
Ceiling & Door & Chair & Curtain \\
Floor & Trim & Toilet & TV \\
Skylight & Area rug & Refrigerator & Towel \\
Wall divider & Wall hanging & Kitchen cabinet & Clothes in closet \\
& Vent & Sink & Box \\
\hline
\end{tabular}


Table 7. Categories and subcategories used to describe object materials

\begin{tabular}{|c|c|c|c|c|}
\hline Impermeable & $\begin{array}{c}\text { Permeable Hard } \\
\text { Surface }\end{array}$ & $\begin{array}{c}\text { Permeable } \\
\text { Wall/Ceiling } \\
\end{array}$ & Plush & Misc. \\
\hline Metal & $\begin{array}{l}\text { Finished laminate } \\
\text { \& wood }\end{array}$ & $\begin{array}{l}\text { Painted } \\
\text { plaster }\end{array}$ & $\begin{array}{l}\text { Thin fabric } \\
\text { (cloth class } 1 \text { ) }\end{array}$ & Wicker \\
\hline Glass & Unfinished wood & $\begin{array}{l}\text { Painted } \\
\text { wallboard }\end{array}$ & $\begin{array}{l}\text { Medium fabric } \\
\text { (cloth class } 2 \text { ) }\end{array}$ & Paper \\
\hline Ceramic & Painted wood & $\begin{array}{l}\text { Wall papered } \\
\text { wallboard }\end{array}$ & $\begin{array}{l}\text { Stuffed fabric } \\
\text { (cloth class } 3 \text { ) }\end{array}$ & \\
\hline Porcelain & Plastic & & Carpet \& rug & \\
\hline \multirow[t]{2}{*}{ Tile } & & & $\begin{array}{l}\text { Carpet with } \\
\text { cushion }\end{array}$ & \\
\hline & & & $\begin{array}{l}\text { Upholstery with } \\
\text { foam }\end{array}$ & \\
\hline
\end{tabular}

Table 8. Uncertainties introduced by grouping small objects $\left(<0.2 \mathrm{~m}^{2}\right)$ into three area categories

\begin{tabular}{lcccc}
\hline Area Category & $\begin{array}{c}\text { No. of } \\
\text { Objects in } \\
\text { Group }\end{array}$ & $\begin{array}{c}\text { Measured } \\
\text { Surface Area } \\
\left.\mathbf{( m}^{\mathbf{2}}\right)\end{array}$ & $\begin{array}{c}\text { Estimated } \\
\text { Surface Area } \\
\left(\mathbf{m}^{\mathbf{2}}\right)\end{array}$ & $\begin{array}{c}\text { (Est. - Meas.)/ } \\
\text { Measured } \\
\mathbf{( \% )}\end{array}$ \\
\hline 300 to $600 \mathrm{~cm}^{2}$ & 15 & 0.57 & 0.68 & +19.3 \\
601 to $1400 \mathrm{~cm}^{2}$ & 15 & 1.49 & 1.50 & +0.7 \\
1401 to $1900 \mathrm{~cm}^{2}$ & 9 & 1.85 & 1.49 & -19.4 \\
300 to $1900 \mathrm{~cm}^{2}$ & 39 & 3.91 & 3.67 & -6.1 \\
\hline
\end{tabular}


Table 9. Summary statistics for surface area-to-volume ratios of selected categorized objects by room type

\begin{tabular}{|c|c|c|c|c|}
\hline \multirow[b]{2}{*}{ Object Description } & \multirow[b]{2}{*}{ Category* } & \multicolumn{3}{|c|}{ Surface Area-to-Volume Ratio $\left(\mathrm{m}^{2} \mathrm{~m}^{-3}\right)$; Median (Range), $n$} \\
\hline & & Common Area & Bedroom/Office & Bathroom \\
\hline $\begin{array}{l}\text { Painted/papered walls \& } \\
\text { ceiling }\end{array}$ & Env. & $0.97(0.24-1.32), 12$ & $1.19(0.39-1.67), 14$ & $1.55(0.85-2.64), 7$ \\
\hline Wall-to-wall carpeting & Env. & $0.28(0.21-0.38), 4$ & $0.26,1$ & -- \\
\hline Exposed wood flooring & Env. & $0.25(0.02-0.37), 7$ & $0.26(0.03-0.41), 12$ & $0.38,1$ \\
\hline Resilient vinyl flooring & Env. & $0.15(0.01-0.34), 3$ & $0.29,1$ & $0.22(0.15-0.30), 5$ \\
\hline Painted doors \& wood trim & Env. Feat. & $0.25(0.02-1.04), 12$ & $0.21(0-0.40), 14$ & $0.19(0.10-0.40), 6$ \\
\hline Windows \& mirrors & Env. Feat. & $0.04(0-0.12), 10$ & $0.09(0.04-0.26), 14$ & $0.07(0.01-0.17), 7$ \\
\hline Area rugs & Env. Feat. & $0.06(0.01-0.09), 5$ & $0.07(0.02-0.21), 7$ & $0.07(0.04-0.10), 6$ \\
\hline $\begin{array}{l}\text { Upholstered furniture \& } \\
\text { bedding }\end{array}$ & Stnd. Item & $0.16(0.02-0.22), 8$ & $0.20(0.02-0.46), 14$ & -- \\
\hline Hard surface furniture & Stnd. Item & $0.48(0.26-0.67), 11$ & $0.61(0.33-1.01), 14$ & $0.36(0.12-0.62), 7$ \\
\hline Tile \& ceramic fixtures & Stnd. Item & $0.04(0-0.10), 3$ & $0.01,1$ & $1.10(0.48-2.36), 7$ \\
\hline $\begin{array}{l}\text { Electronic equipment, lights, } \\
\text { trash cans, plastic bottles \& } \\
\text { other misc. }\end{array}$ & Misc. & $0.15(0.03-0.37), 10$ & $0.25(0.06-0.87), 14$ & $0.65(0.22-1.18), 7$ \\
\hline $\begin{array}{l}\text { Towels, clothing, curtains \& } \\
\text { other plush misc. }\end{array}$ & Misc. & $0.17(0-0.39), 8$ & $0.27(0-0.89), 9$ & $0.35(0.03-0.70), 6$ \\
\hline Small objects $\left(<0.2 \mathrm{~m}^{2}\right)$ & Misc. & $0.07(0-0.17), 11$ & $0.16(0.02-0.26), 14$ & $0.08(0.03-0.16), 7$ \\
\hline
\end{tabular}

*Object category from Table 6; Env. = Envelope, Env. Feat. = Envelope Feature, Stnd. Item = Standing Item 
Table 10. Summary statistics for surface area-to-volume ratios of surface materials by room type

\begin{tabular}{|c|c|c|c|c|}
\hline \multirow[b]{2}{*}{ Material Description } & \multirow[b]{2}{*}{ Category* } & \multicolumn{3}{|c|}{ Surface Area-to-Volume Ratio $\left(\mathrm{m}^{2} \mathrm{~m}^{-3}\right)$; Median (Range), $n$} \\
\hline & & Common Area & Bedroom/office & Bathroom \\
\hline Metal & Imperm. & $0.07(0.00-0.15), 10$ & $0.05(0-0.22), 12$ & $0.08(0.03-0.22), 5$ \\
\hline Glass & Imperm. & $0.06(0.01-0.12), 11$ & $0.11(0.04-0.34), 14$ & $0.08(0.03-0.17), 7$ \\
\hline Ceramic, porcelain \& tile & Imperm. & $0.03(0.00-0.12), 6$ & $0(0-0.01), 4$ & $1.12(0.48-2.36), 7$ \\
\hline Finished wood & Hard Surf. & $0.54(0.16-1.08), 12$ & $0.73(0.10-1.12), 14$ & $0.26(0.01-0.75), 7$ \\
\hline Unfinished wood & Hard Surf. & $0.04(0.00-0.12), 9$ & $0.12(0-0.53), 12$ & -- \\
\hline Painted wood & Hard Surf. & $0.38(0.02-1.05), 12$ & $0.34(0-1.27), 14$ & $0.44(0.12-1.11), 7$ \\
\hline Vinyl (PVC) & Hard Surf. & $0.15(0.02-0.35), 3$ & $0.30,1$ & $0.75(0.34-1.36), 6$ \\
\hline Other plastic & Hard Surf. & $0.23(0.04-0.47), 11$ & $0.40(0.06-0.98), 12$ & $0.23(0.11-0.36), 7$ \\
\hline $\begin{array}{l}\text { Painted/papered plaster \& } \\
\text { wallboard }\end{array}$ & Wall/Ceil. & $0.97(0.24-1.32), 12$ & $1.22(0.39-1.86), 14$ & $1.55(0.85-2.63), 7$ \\
\hline Thin fabrics & Plush & $0.19(0.01-0.48), 9$ & $0.27(0.01-1.35), 14$ & $0.37(0.03-0.70), 7$ \\
\hline $\begin{array}{l}\text { Upholstery, padded fabrics, } \\
\text { carpet, carpet with cushion }\end{array}$ & Plush & $0.26(0.00-0.56), 9$ & $0.28(0.04-0.66), 14$ & $0.08(0.03-0.10), 3$ \\
\hline Paper & Misc. & $0.05(0.00-0.14), 10$ & $0.10(0-0.71), 12$ & $0.01(0-0.04), 4$ \\
\hline
\end{tabular}

*Material category from Table 7; Imperm. = Impermeable, Hard Surf. = Permeable Hard Surface, Wall/Ceil. = Permeable Wall/Ceiling 


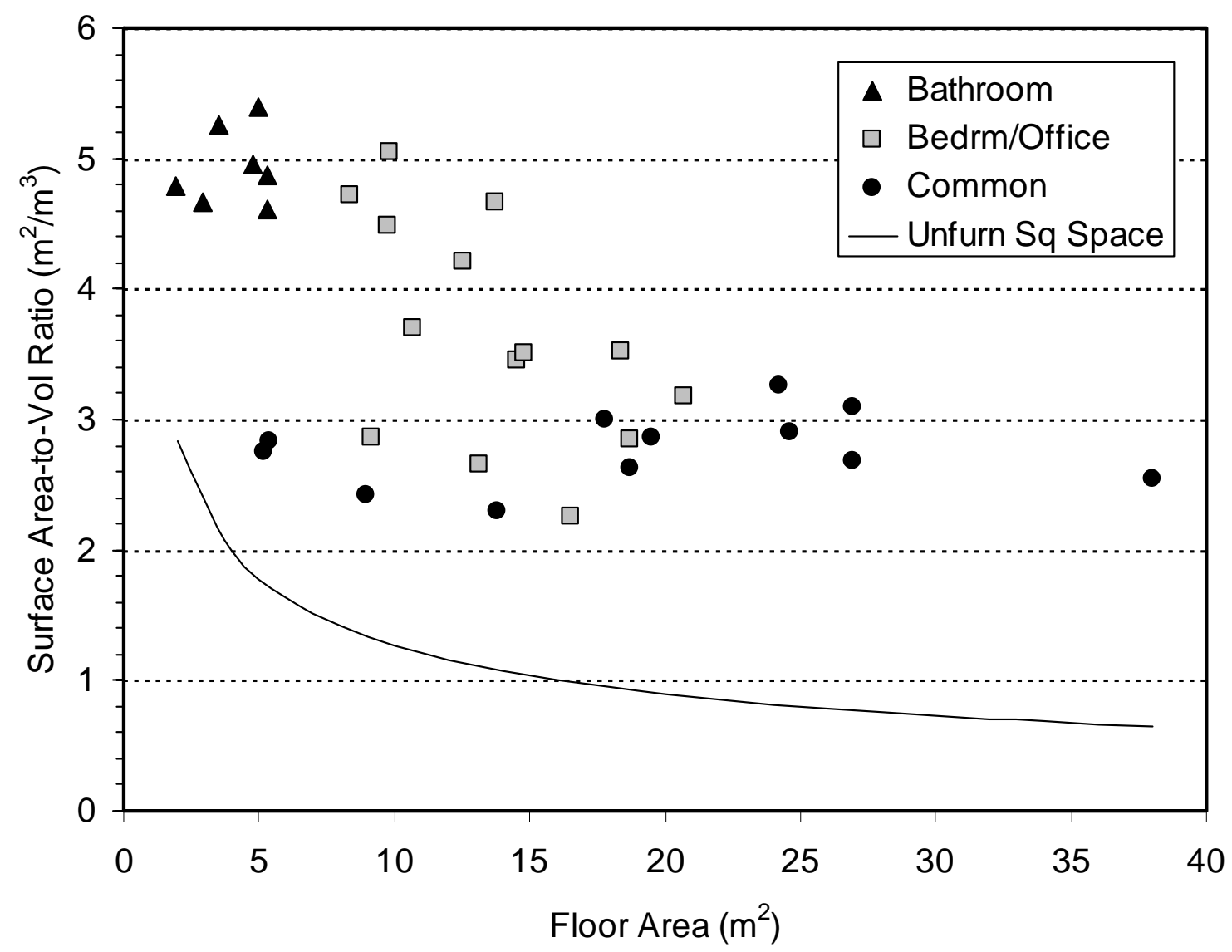

Figure 1. Total surface area-to-volume ratios for 33 study rooms by room type. Envelope surface area-to-volume ratios for unfurnished square rooms with 2.43-m ceiling height are shown for comparison. 


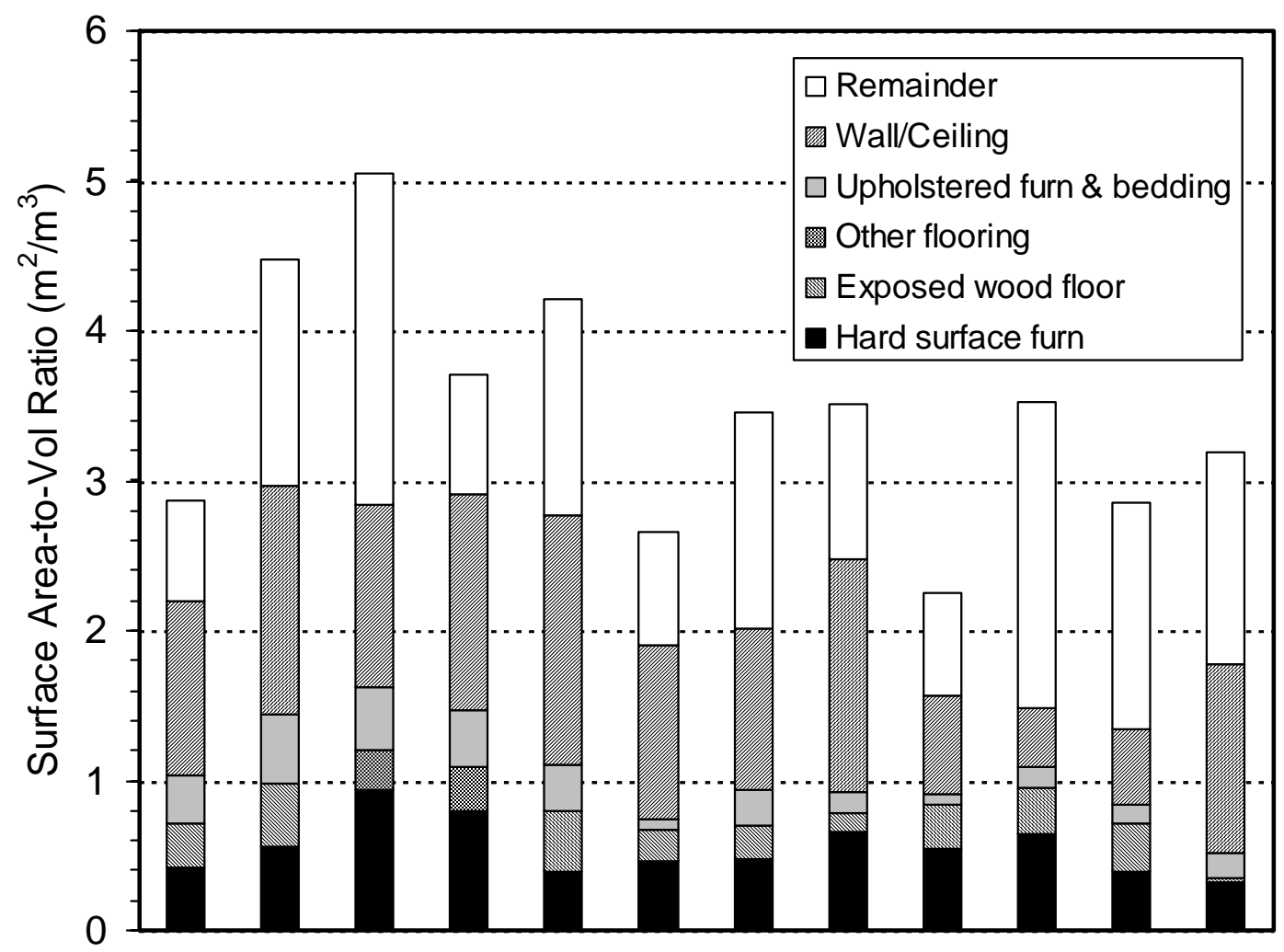

Figure 2. Total surface area-to-volume ratios and ratios for subcategories of commonly encountered objects in 12 study bedrooms. Rooms are shown in order of increasing floor area from left to right. 